\title{
Hardness Response Surface for U-7.5Nb-2.5Zr Alloy: A Study of Recovery/Recrystallization and Phase Transformation Interactions
}

\author{
DENISE ADORNO LOPES, ANGELO JOSÉ DE OLIVEIRA ZIMMERMANN, \\ THOMAZ AUGUSTO GUISARD RESTIVO, and ANGELO FERNANDO PADILHA
}

\begin{abstract}
Uranium alloys in monolithic form are an option for creating advanced nuclear fuels with very high uranium density, low isotopic enrichment, and high thermal conductivity. One aspect of the metallic fuel development is to demonstrate the retention of similar $\gamma$-phase microstructure $\left(\gamma^{\mathrm{s}}\right)$ in the fuel alloy after fabrication and during the irradiation process. Unfortunately, there are few recent systematic studies in uranium alloys. Additionally, none of them are addressing the theme of recovery/recrystallization and phase transformations interactions that compose the basic metallurgical knowledge to manufacture nuclear fuel plates. This paper discusses this theme for U-7.5Nb-2.5Zr alloy employing a multivariate statistical technique, namely response surface methodology, to analyze the effect of the following process variables: degree of deformation, temperature, and time. Based on the results, in the range studied, the authors demonstrated that at low temperatures, the interaction between the recovery phenomenon and precipitation of metastable $\alpha^{\prime \prime}$ phase (isothermal martensitic shear transformation) shows a dependence with the degree of deformation, with prevalence of recovery for higher levels of this parameter. Interaction between $\alpha+\gamma_{3}$ phase nucleation and recrystallization is limited to a narrow temperature range $\left[\sim 848 \mathrm{~K}\right.$ to $923 \mathrm{~K}\left(575^{\circ} \mathrm{C}\right.$ to $\left.\left.650^{\circ} \mathrm{C}\right)\right]$ and during the first hour of annealing. Additionally, the series of phase transformations, $\gamma \rightarrow \gamma^{\mathrm{s}} \rightarrow \gamma^{\mathrm{o}} \rightarrow \alpha^{\prime \prime}$, produced by shear was observed to be strongly dependent on crystallographic orientations and this fact could be used to enhance the retention of the metastable $\gamma^{\mathrm{s}}$ phase.
\end{abstract}

DOI: $10.1007 / \mathrm{s} 40553-015-0052-y$

(C) ASM International (ASM) and The Minerals, Metals \& Materials Society (TMS) 2015

\section{INTRODUCTION}

THE current thermal power reactors use less than 1 pet of the energy contained in uranium. ${ }^{[1]}$ Thus, one of the current challenges in the development of nuclear technology is the conception of new plants and fuel elements that improve the efficiency of the energy provided by nuclear fission. ${ }^{[2]}$ Another strong motivator for the development of new concepts of nuclear fuel is the establishment of the maximum level of isotopic enrichment to 20 pct U-235, in order to prevent proliferation as a consequence of using high-enriched uranium (HEU) for non-peaceful purposes. In view of these

DENISE ADORNO LOPES, Postdoctoral Fellow, is with the Laboratório de Materiais Nucleares - LABMAT, Centro Tecnológico da Marinha em São Paulo, Rod. Sorocaba-Iperó km 12.5, 18560-000 Iperó, SP Brazil, and also with the Escola Politécnica da Universidade de São Paulo, Av. Prof. Mello Moraes, 2463 05508-030 São Paulo, SP, Brazil. Contact email: deniseadorno@hotmail.com ANGELO JOSÉ DE OLIVEIRA ZIMMERMANN, Postdoctoral Fellow, is with the Laboratório de Materiais Nucleares - LABMAT, Centro Tecnológico da Marinha em São Paulo. THOMAZ AUGUSTO GUISARD RESTIVO, Associate Professor, is with the Escola Politécnica da Universidade de São Paulo, and also with the Universidade de Sorocaba, UNISO, Rod. Raposo Tavares km 92.5, 18023-000 Sorocaba, SP, Brazil. ANGELO FERNANDO PADILHA, Titular Professor, is with the Escola Politécnica da Universidade de São Paulo. Manuscript submitted November 8, 2014.

Article published online July 9, 2015 challenges, metal fuels have been considered good alternatives to $\mathrm{UO}_{2}$. They allow a combination of high fissile density, high thermal conductivity, and easy implementation in plate geometry, an efficient design for heat transfer in comparison to the rod fuel. ${ }^{[3]}$ Additionally, metallic fuels have low manufacturing cost in comparison with ceramic fuel and an easier reprocessing cycle. ${ }^{[4,5]}$

Uranium metal exhibits polymorphism with three crystallographic phases: $\alpha-\mathrm{U}$ (orthorhombic, 4 atoms/cell), $\beta$-U (tetragonal, 30 atoms/cell), and $\gamma$-U (bodycentered cubic, 2 atoms/cell). Only the $\gamma$-phase shows isotropic physical properties and dimensional stability under irradiation. ${ }^{[6]}$ For this reason, there is more literature focused on alloy systems that stabilize the $\gamma$ phase. ${ }^{[7]}$

Furthermore, the number of allotropic phases presented in uranium alloys is larger than the three phases of pure uranium. Additional metastable phases are found $\left(\alpha^{\prime}, \alpha^{\prime \prime}, \gamma^{\mathrm{s}}, \gamma^{\mathrm{o}}\right)$ formed by martensitic transformations. ${ }^{[8]}$ Here, $\alpha^{\prime}$ is a distorted $\alpha$, primarily involving a contraction of the $b$ lattice parameter; $\alpha^{\prime \prime}$ is a monoclinic distortion of martensitic alpha $\left(\alpha^{\prime}\right) ; \gamma^{\circ}$ is a tetragonal distortion of $\alpha$; and $\gamma^{\mathrm{s}}$ is an even less severe deviation from the BCC structure. The transformation sequence is generally described as $\alpha \rightarrow \beta \rightarrow \alpha^{\prime} \rightarrow \alpha^{\prime \prime} \rightarrow \gamma^{\circ} \rightarrow$ $\gamma^{\mathrm{s}} \rightarrow \gamma^{[8,9]}$ and is dependent on the type and on the amount of alloy elements (Figure 1). ${ }^{[8]}$ In uranium 


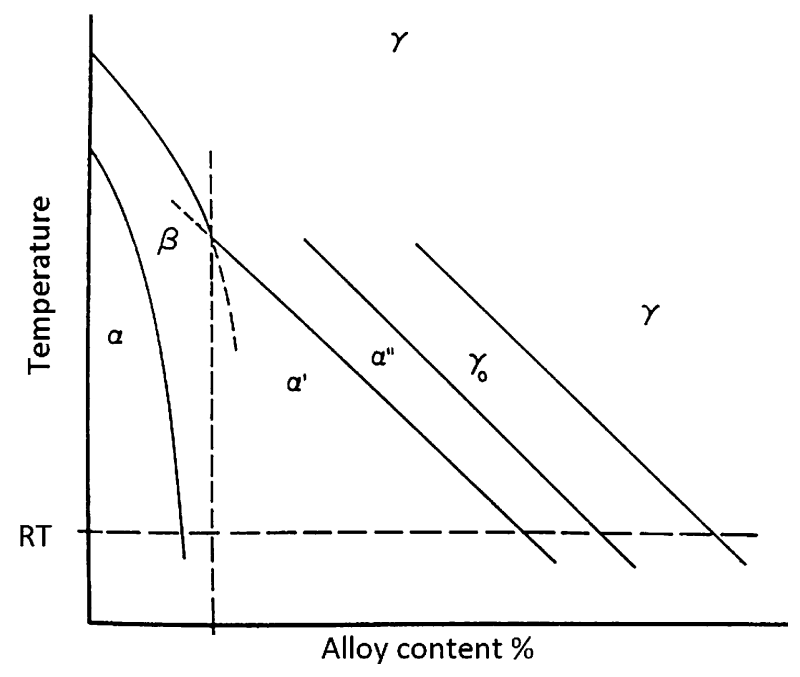

Fig. 1-Schematic representation of $\gamma$-phase transformation temperatures during cooling at a fixed rate as a function of alloy content ${ }^{[8]}$.

alloys, the importance of these martensitic transformations lies primarily in the possibility of obtaining an isotropic microstructure at low temperature, in order to increase the dimensional stability in irradiation and thermal cycling conditions. Hence, one important aspect in the metallic nuclear fuel development is to promote the retention of a martensitic microstructure similar to $\gamma$-phase (i.e., $\gamma^{\mathrm{s}}$ ) in the fuel alloy after fabrication and during the irradiation process.

However, a series of events and technological problems have caused a recess in the metal nuclear fuel research. ${ }^{[10]}$ For this reason, there are few recent systematic studies on classical physical metallurgy themes for uranium alloys, such as recovery, recrystallization, and grain growth. Furthermore, the study on the interaction between phase precipitation and recrystallization in metallic alloys was developed in this period when research with uranium alloy was in decline ${ }^{[11-15]}$ and, as a consequence, this issue has never been addressed for uranium alloy systems.

In previous literature, a widely studied ternary uranium alloy was the $\mathrm{U}-7.5 \mathrm{Nb}-2.5 \mathrm{Zr}$ named "Mulberry."[16] A considerable number of data can be found regarding phase transformation for this alloy. ${ }^{[17-21]}$ A reasonable consensus exists on the identification of the phases present at high temperatures [range $673 \mathrm{~K}$ to $973 \mathrm{~K}\left(400{ }^{\circ} \mathrm{C}\right.$ to $\left.700{ }^{\circ} \mathrm{C}\right)$ ], being a pearlite $\left(\alpha+\gamma_{3}\right)$ formed by diffusion process. However, in the range of $373 \mathrm{~K}$ to $673 \mathrm{~K}\left(100{ }^{\circ} \mathrm{C}\right.$ to $\left.400{ }^{\circ} \mathrm{C}\right)$, divergences persist concerning the identification of metastable phases $\gamma^{\circ}$ and $\alpha^{\prime \prime} .^{[17-21]}$ With respect to data available in the literature regarding the recrystallization in "Mulberry" alloy, a brief investigation was made by Peterson and Vandervoort. ${ }^{[21]}$ In their work, no discussion was made about the hardness behavior, i.e., about the interacting phenomenon of phase precipitation and recrystallization. In a more recent paper, the present authors showed an isochronal recrystallization curve ${ }^{[22]}$ and mentioned the theme, but not in a systematic study that could explain the influence of process parameters.
The experiments described herein were designed to contribute to understand the behavior of the U-7.5Nb$2.5 \mathrm{Zr}$ alloy regarding the phenomenon of interaction between phase precipitation and recovery/recrystallization during annealing after mechanical deformation. In this paper, this theme is explored employing a multivariate statistical technique, namely response surface methodology $(\mathrm{RSM})^{[23]}$ to analyze the influence of the following process variables: degree of deformation, temperature, and time. This physical metallurgy study aims to increase reliability of monolithic nuclear fuel manufacture.

\section{EXPERIMENTAL METHOD}

\section{A. Alloy Preparation}

Detailed fabrication of the alloy, which was induction melted, can be found in Reference 24 The U-7.5Nb$2.5 \mathrm{Zr}$ alloy (wt pct) was prepared in a vacuum induction melting furnace. The sample plate for the rolling process was cut from the induction melted ingot in the longitudinal direction. The chemical compositions of the ascast alloy $\mathrm{U}-7.5 \mathrm{Nb}-2.5 \mathrm{Zr}$ were obtained by Inductively Coupled Plasma Optical Emission Spectrometry (ICPOES) quantitative analyses. Chemical analysis to determine the amount of carbon, nitrogen, and oxygen impurities was performed using a LECO IR-412 carbon determinator with an HF-400 induction furnace ${ }^{[25]}$ and a LECO TC-436 nitrogen/oxygen analyzer module with an EF-400 furnace module. ${ }^{[26]}$ Two samples, taken from different positions in the longitudinal direction of the casting piece (top and center), were analyzed to check their homogeneity, as shown in Table I. ${ }^{[2]}$

After melting, the alloy was heat treated at $1273 \mathrm{~K}$ $\left(1000{ }^{\circ} \mathrm{C}\right)$ for 5 hours in an argon atmosphere followed by water quenching to obtain a homogeneous microstructure of $\gamma$-phase at room temperature. Retention of $\gamma$-phase was verified by measurements of Vickers hardness (loaded with 500 gf for 10 seconds), optical microscopy, and Xray diffraction. Preparation of samples for all the microstructural analysis was carried out according to the methodology proposed by Kelly et al. ${ }^{[27]}$

\section{B. Experimental Design}

For the present experiment, a central composite design was used, ${ }^{[23]}$ because it requires less interaction to define the parameters used for input in a RSM. The central composite design was presented by Box and Wilson. ${ }^{[2]}$ This design consists of (1) a factorial part; (2) an axial part design, often a start design in which experimental points are at a distance $\alpha$ from its center; and (3) a central point. Only the factorial and central part were used in this experiment due to the linear behavior observed for the interactions between variables.

Three process variables were used as the factors with low, medium, and high levels, being

(i) Degree of deformation 20, 50, and 80 pct: The samples were submitted to deformation steps by cold rolling close to 10 pct reduction in a duo-mill with a $485-\mathrm{mm}$ radius cylinder. 
Table I. Chemical Composition (Weight Percent) of the Induction Melted Alloy ${ }^{[24]}$

\begin{tabular}{lll}
\hline & \multicolumn{2}{c}{ U-7.5Nb-2.5Zr } \\
\cline { 2 - 3 } Element (Wt Pct) & \multicolumn{1}{c}{ Top } & Center \\
\hline $\mathrm{U}$ & 90.03 & 89.83 \\
$\mathrm{Nb}$ & 7.35 & 7.59 \\
$\mathrm{Zr}$ & 2.4 & 2.36 \\
$\mathrm{C}$ & 0.021 & 0.023 \\
$\mathrm{~N}$ & 0.0010 & 0.0012 \\
$\mathrm{O}$ & 0.0042 & 0.0040 \\
$\mathrm{Al}$ & 0.008508 & 0.009745 \\
$\mathrm{Fe}$ & 0.02591 & 0.03016 \\
$\mathrm{Cu}$ & 0.00503 & 0.006446 \\
\hline
\end{tabular}

Table II. Experimental Matrix for Design Based on a Three Level Variable Study

\begin{tabular}{|c|c|c|c|c|}
\hline Type & Exp. & $\begin{array}{c}\text { Degree } \\
\text { of Deformation } \\
\text { (pct) }\end{array}$ & $\begin{array}{c}\text { Temperature } \\
{\left[\mathrm{K}\left({ }^{\circ} \mathrm{C}\right)\right]}\end{array}$ & $\begin{array}{l}\text { Time } \\
\text { (h) }\end{array}$ \\
\hline Factorial design & 1 & 20 & $973(700)$ & 1 \\
\hline Factorial design & 2 & 20 & $473(200)$ & 1 \\
\hline Central point & 3 & 50 & $723(450)$ & 2.5 \\
\hline Factorial design & 4 & 80 & $473(200)$ & 4 \\
\hline Factorial design & 5 & 80 & $973(700)$ & 4 \\
\hline Factorial design & 6 & 20 & $973(700)$ & 4 \\
\hline Central point & 7 & 50 & $723(450)$ & 2.5 \\
\hline Additional point & 8 & 50 & $973(700)$ & 1 \\
\hline Factorial design & 9 & 80 & $473(200)$ & 1 \\
\hline Factorial design & 10 & 80 & $973(700)$ & 1 \\
\hline Factorial design & 11 & 20 & $473(200)$ & 4 \\
\hline
\end{tabular}

(ii) Annealing temperature $473 \mathrm{~K}, 723 \mathrm{~K}$, and $973 \mathrm{~K}$ $\left(200{ }^{\circ} \mathrm{C}, 450{ }^{\circ} \mathrm{C}\right.$, and $\left.700{ }^{\circ} \mathrm{C}\right)$;

(iii) Annealing time 1, 2.5, and 4 hours.

All heat treatments were performed under argon atmosphere followed by water quenching to stabilize the solid solution structure formed.

The responses collected for all the levels were

- Vickers hardness (loaded with 500 gf for 10 seconds), in the as-polished surface finish. The data presented are average and include the error (standard deviations) of at least ten indentations.

- Grain size was determined according to ASTM E112-96 ${ }^{[28]}$ using a Linear Intercept Procedure, conducted using a Zeiss DSM960A. Samples were analyzed after electroetching with a solution of $10 \mathrm{pct}$ Oxalic Acid at $\sim 3$ to $4 \mathrm{~V}$ for $\sim 3$ to 4 seconds.

- Phase analysis using X-ray diffraction. The analysis was conducted by scanning from 20 deg to 80 deg at a scan rate of $1.0 \mathrm{deg} / \mathrm{s}$ using a Shimatzu XRD-6000 in theta-theta geometry. The X-ray tube operated at a $40 \mathrm{kV}$ voltage and a $40 \mathrm{~mA}$ current. All the measurements were performed on a polished sample surface. The XRD data were evaluated using Rietveld analysis (GSAS software ${ }^{[29]}$ ).
Table II shows the experimental matrix used herein.

The experiment point 8 in Table II configures an additional experiment inserted in the design due to the results obtained in a previous work, ${ }^{[22]}$ in which the alloy does not present a $\gamma$ phase state totally recrystallized for 1 hour annealing at $973 \mathrm{~K}\left(700{ }^{\circ} \mathrm{C}\right)$.

\section{RESULTS AND DISCUSSION}

Figure 2 shows the micrographs taken perpendicular to the rolling of the samples (i.e., parallel with the rolling direction) with degree of deformation of 20 and 80 pct, annealed at $473 \mathrm{~K}\left(200{ }^{\circ} \mathrm{C}\right)$ for 1 and 4 hours. No significant microstructural changes were observed for 1 hour annealing time in either levels of reduction. However, it must be noted that samples annealed for a longer time (4 hours) showed grain substructures, which may be associated with the decomposition of metastable $\gamma^{\mathrm{s}}$ phase in structures $\gamma^{\mathrm{o}}$ or $\alpha^{\prime \prime}$.

Vickers hardness values as a function of heat treatment time are provided in Figure 3, which shows the results for annealing at low temperature $(473 \mathrm{~K})$ in normal and parallel surface to the rolling direction. The values show a relative increase in Vickers hardness with increased annealing duration for the sample with $20 \mathrm{pct}$ reduction, which can be associated with the precipitation of $\alpha^{\prime \prime}$ (an increase in hardness would be expected due to the higher hardness of $\alpha-\mathrm{U}$ and the fine distribution of the phases produced) ${ }^{[30]}$ For the $80 \mathrm{pct}$ degree of deformation, there is a relative decrease (about $7 \mathrm{pct}$ ) that may be associated with the occurrence of the recovery phenomenon. To eliminate effects of anisotropy, caused by crystallographic texture, measurements were performed in complementary directions (normal and parallel) as summarized in Figure 3.

It must be noted that previous studies of $\beta$-phase decomposition in uranium alloys found martensitic transformations associated with C type curves (TTT diagram) at low temperature. Such transformations have an isothermal growth mechanism, for which the transformation temperature depends on the alloy composition. Growth is clearly thermally activated in this case. ${ }^{[8]}$ However, the mechanism for this isothermal martensitic transformation is not yet accurately understood.

$\mathrm{U}-7.5 \mathrm{Nb}-2.5 \mathrm{Zr}$ alloy also has this isothermal martensitic transformation for $\alpha^{\prime \prime}$ phase precipitation. ${ }^{[16-20]}$ Thus, there are two types of martensitic transformations in the U-7.5Nb-2.5Zr alloy, (i) $\gamma \rightarrow \gamma^{\mathrm{s}}$ being an athermic transformation resulting in a decrease in hardness and (ii) $\gamma^{\mathrm{s}} \rightarrow \alpha^{\prime \prime}$ which is an isothermal transformation at low temperature associated with an increase in hardness. ${ }^{[31]}$ This fact sheds some additional insight about the hardness behavior of the current studied alloy; hardness is a parameter which has an opposite behavior to the phenomenon of the $\alpha^{\prime \prime}$ phase precipitation (increase) and recovery (decrease).

Based on this knowledge, a hypothesis for the behavior shown in Figure 3 is that for lower degree of deformation $(20 \mathrm{pct})$, the sample stores energy introduced by rolling and, in posterior annealing, uses that energy as a driving force to aid the formation of $\alpha^{\prime \prime}$, with 


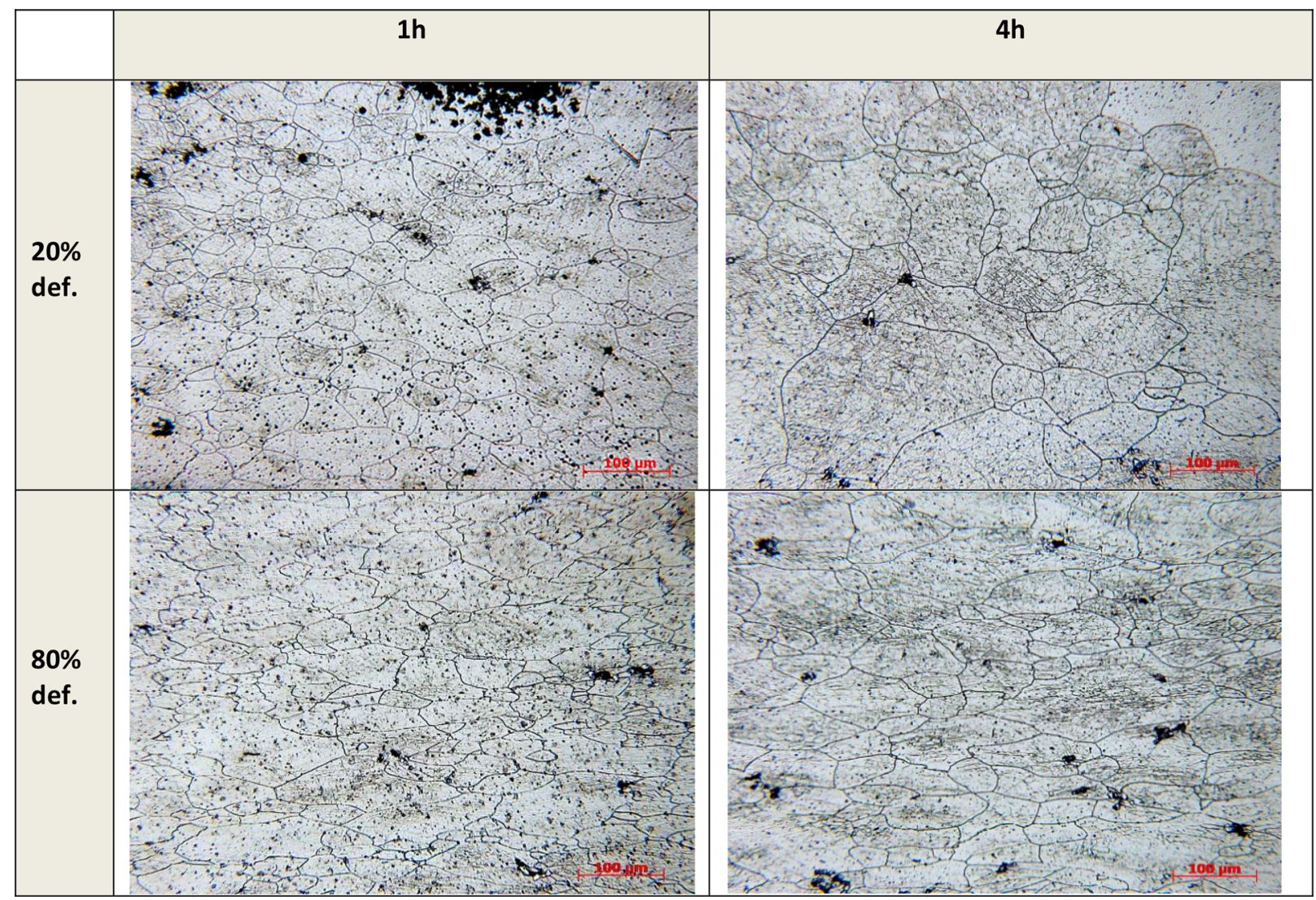

Fig. 2 - Optical micrographs of U-7.5Nb-2.5Zr alloy cold rolled $\left(20\right.$ and 80 pct reduction) and annealed at $473 \mathrm{~K}\left(200{ }^{\circ} \mathrm{C}\right)(1$ and $4 \mathrm{~h})$ taken perpendicular to the rolling direction.

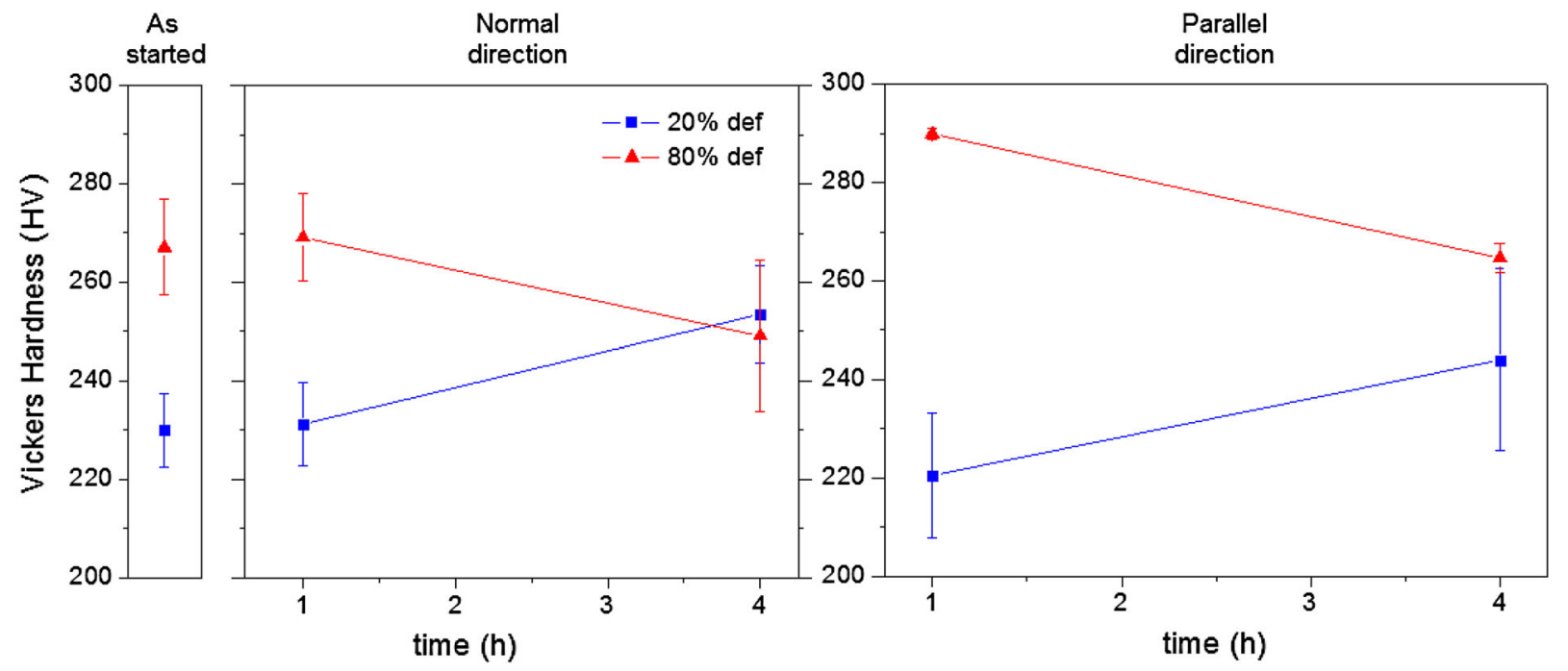

Fig. 3-Vickers hardness $v s$ time for isothermal annealing at $473 \mathrm{~K}\left(200^{\circ} \mathrm{C}\right)$ for 20 and 80 pct degrees of deformation. "As started" are the deformed samples. The data were recorded in distinct directions, normal (left) and parallel (right) to the rolling direction.

a consequent increase in hardness. For a higher degree of deformation, the sample stored enough energy to promote both $\alpha$ " precipitation and recovery. In this case, recovery occurs with such intensity that it overcomes the hardening promoted by $\alpha^{\prime \prime}$ precipitation.
Based on these results, a competition between $\alpha^{\prime \prime}$ precipitation and recovery is verified. This fact is something unusual in the literature since these isothermal martensitic transformations are not extensively related. ${ }^{[32]}$ 


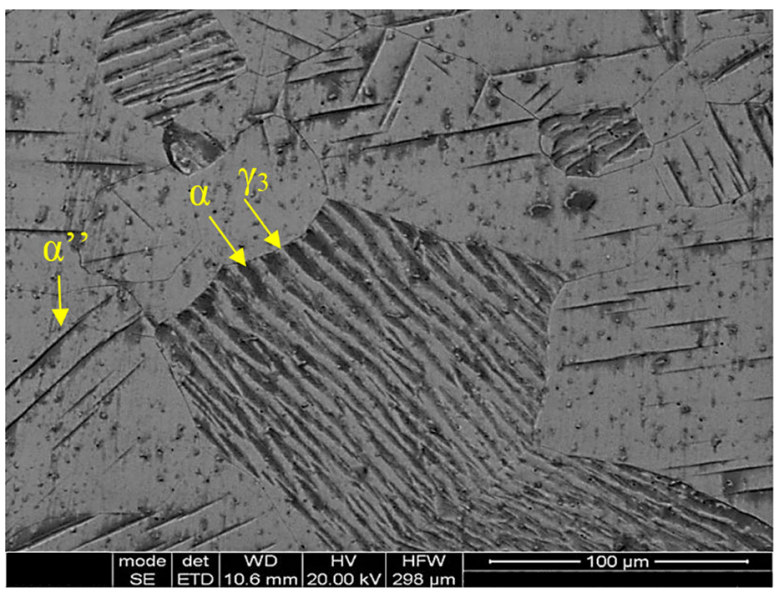

Fig. 4-Electron micrograph with secondary electrons for U-7.5Nb$2.5 \mathrm{Zr}$, deformed $50 \mathrm{pct}$ and annealed at $723 \mathrm{~K}\left(450^{\circ} \mathrm{C}\right)$ for $2.5 \mathrm{~h}$ Precipitation of $\alpha+\gamma_{3}$ in $\gamma^{\mathrm{s}}$ deformed grain and band structures possibly $\alpha^{\prime \prime}$.

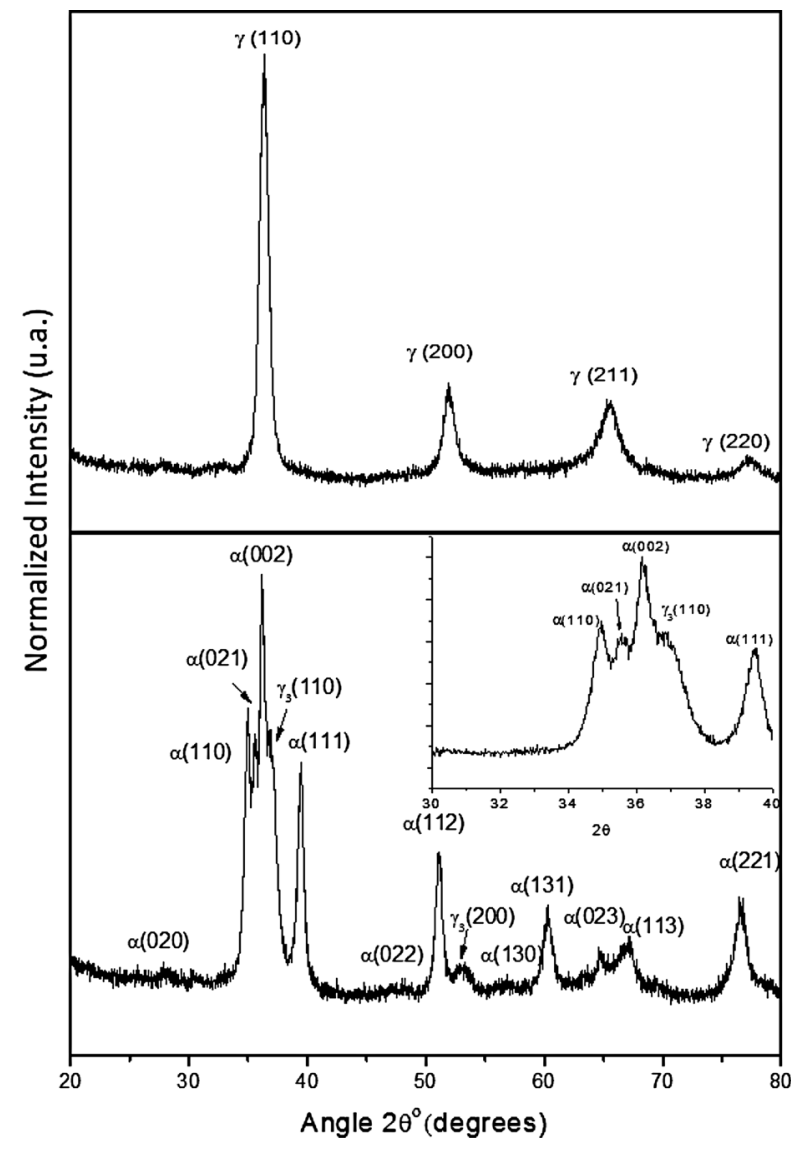

Fig. 5-X-ray diffraction patterns for U-7.5 Nb-2.5Zr cold-rolled deformed 50 pct (top) and annealed at $723 \mathrm{~K}\left(450{ }^{\circ} \mathrm{C}\right.$ ) for $2.5 \mathrm{~h}$ (below), showing decomposition of the $\gamma^{\mathrm{s}}$ in $\alpha+\gamma_{3}$.

Annealing at $723 \mathrm{~K}\left(450^{\circ} \mathrm{C}\right)$ for 2.5 hours of the 50 pct deformed sample (central point in the experiment design) resulted in phase precipitation of $\alpha+\gamma_{3}$ on the $\gamma^{\mathrm{s}}$ deformed grain, producing a highly oriented structure, as shown in Figures 4 and 5. This structure presents a Vickers hardness value of $482.4( \pm 9.48) \mathrm{HV}$.
The alternate plates in these colonies are an orthorhombic phase (lattice parameters $a=2.858 \AA$, $b=5.857 \AA, c=4.963 \AA$ ) and a niobium-rich bcc phase $(a=b=c=3.435 \AA)$ named $\gamma_{3}$. The occurrence of $\gamma_{3}$ phase is evidenced by the shift in the diffraction peaks to higher angles due to the high $\mathrm{Nb}$ content with regard to the $\gamma$ phase. This transformation is similar to the eutectoid decomposition of austenite to form pearlite in steel. Refinement of the diffraction pattern did account for some preferred orientation in (110) in the decomposition $\gamma \rightarrow \alpha+\gamma_{3}$ instead of the normal $(021){ }^{[33]}$ This fact was expected, given the asrolling condition of the $\gamma$ phase, and suggests the occurrence of phase transformation texture.

The microstructure, Vickers hardness, and grain size observed taken perpendicular to the rolling direction for the higher level annealing temperature [973 $\mathrm{K}\left(700^{\circ} \mathrm{C}\right)$ ] are shown in Figures 6 and 7, respectively. No metallographic evidence of phase transformation such as band or acicular microstructure was apparent after quenching.

Recrystallization was found to be very inhomogeneous in 20 pct degree of deformation. Figure 6 clearly shows that for the lowest degree of deformation, there are regions of very small grains possibly formed through multiple nucleation. It was hypothesized that this microstructure may be a consequence from particlestimulated nucleation (PSN) ${ }^{[34]}$ deriving from partial nucleation of $\alpha+\gamma_{3}$ during the heating. However, this hypothesis was not supported, since it would also cause the same effect in the samples deformed by 80 pct. Therefore, this finding clearly demonstrates the occurrence of heterogeneous nucleation due to the low degree of deformation.

The higher slope in the range referring to the first hour observed in Figure $7 \mathrm{a}$ (dashed lines) suggests that the kinetics of recrystallization was accelerated for the highest degree of deformation applied. By setting a linear fit, slopes of -88.8 and $-66.3(\mathrm{HV} / \mathrm{h})$ were obtained for 80 and 20 pct degrees of deformation, respectively, producing a difference of approximately 25 pct in the recrystallization speed. Figure 7(a) also demonstrated a similar slope for the curves to times above 1 hour. This shows that the recrystallization was completed in 1 hour for both degrees of deformation.

Figure $7 \mathrm{~b}$ shows that the resulting grain size is always the highest for the lowest degree of deformation $(20 \mathrm{pct})$. This effect is more pronounced for long annealing times, consistent with the IV recrystallization law. ${ }^{[32]}$ A high degree of deformation will cause more nuclei per unit volume, and consequently smaller grain size.

Despite the single phase microstructure observed metallographically, a more complete overview of the heat treatments effect can be visualized by means of $\mathrm{X}$ ray diffraction patterns. Figure 8 provides $\mathrm{X}$-ray diffraction patterns for each of the annealing conditions investigated for high temperature, and for the homogenized $(1273 \mathrm{~K} / 5 \mathrm{~h}$, Reference 24$)$ and deformed states (20 and 80 pet reduction). After recrystallization, all the patterns showed significant shoulders characteristic of the so-called $\gamma^{\mathrm{o}}$ phase, ${ }^{[9]}$ in contrast to the homogenized 


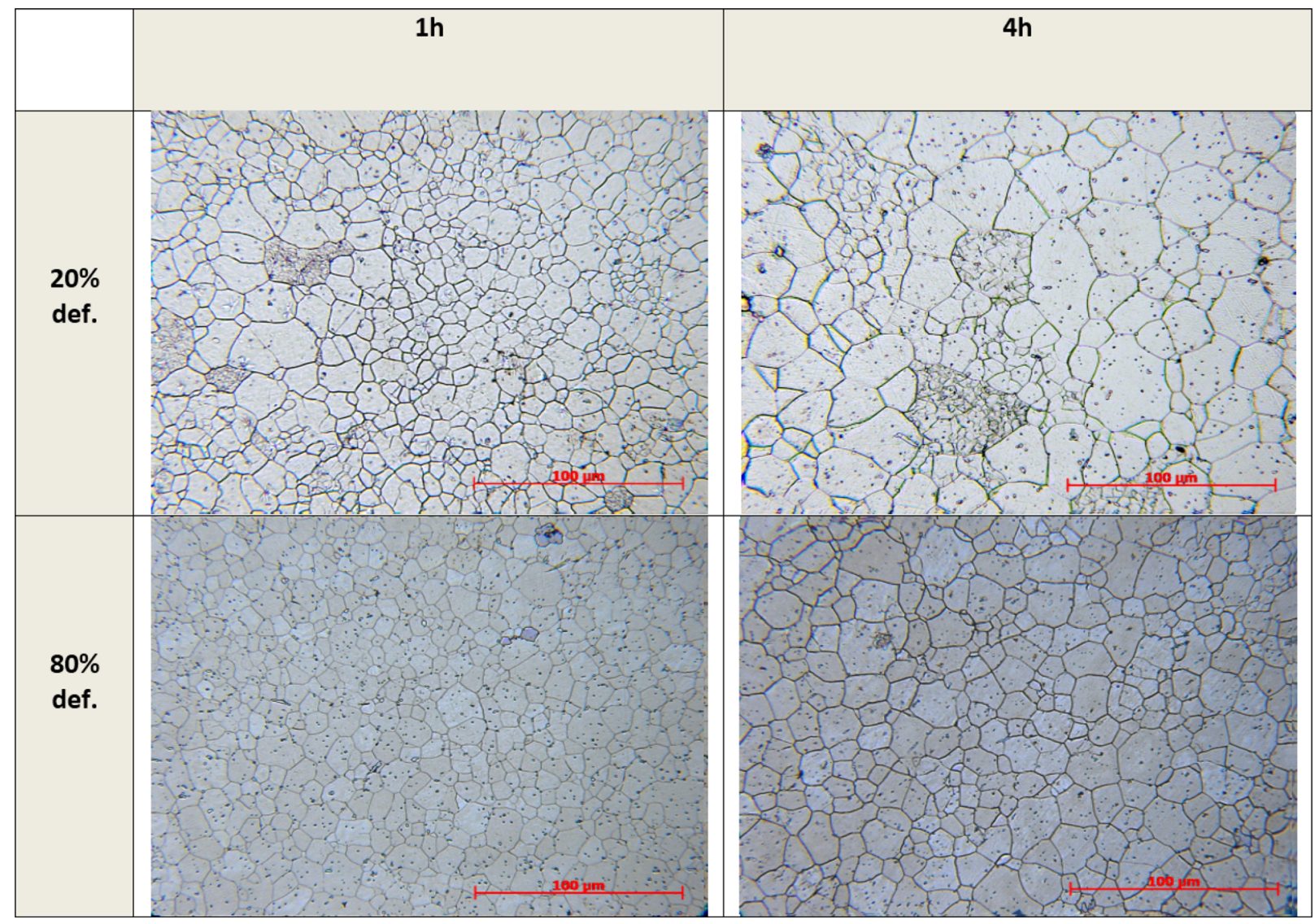

Fig. 6-Micrographs of U-7.5Nb-2. 5Zr alloy cold rolled (20 and 80 pet reduction) and annealed at $973 \mathrm{~K}\left(700{ }^{\circ} \mathrm{C}\right)($ time 1 and $4 \mathrm{~h})$ taken perpendicular to the rolling direction.
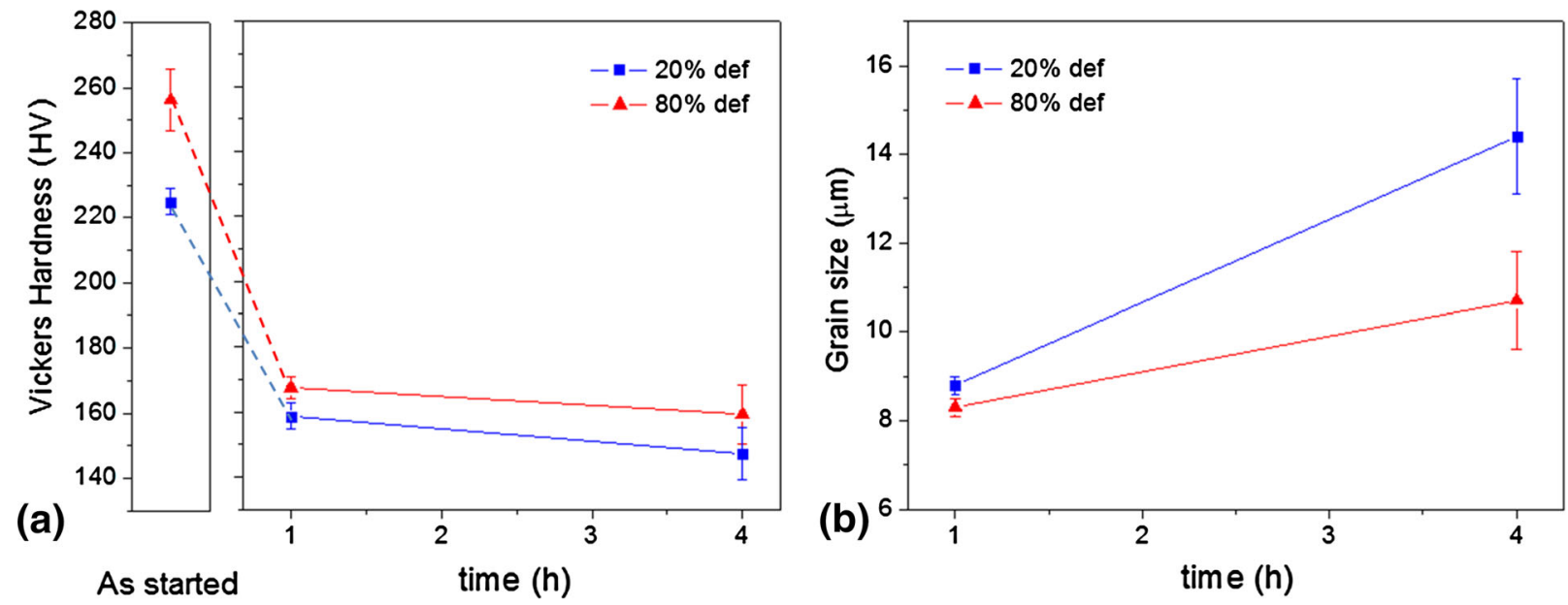

Fig. 7-Vickers Hardness $(a)$ and grain size $(b)$ versus time for isothermal annealing at $973 \mathrm{~K}\left(700{ }^{\circ} \mathrm{C}\right)$ for the degree of deformation of 20 and 80 pct taken perpendicular to the rolling direction. "As started" are the deformed samples. Dashed lines are the linear fits.

and deformed states that present diffraction peaks associated with $\gamma^{\mathrm{s}}$.

Similar changes were observed in the diffraction pattern profiles for the alloy treated at $973 \mathrm{~K}\left(700{ }^{\circ} \mathrm{C}\right)$ with the lattice parameters ranging varied from $a=4.97 \pm 0.02 \AA$ and $c=3.44 \pm 0.03 \AA$ by Rietveld analysis. Additionally, refinement of the diffraction patterns did account for some preferred orientation in (200) and (111) for all samples. The $\mathrm{UO}_{2}$ peaks observed in some conditions are related to a superficial oxidation before the X-ray experiment.

As the heat treatments were performed separately and in random order, the $\gamma^{\circ}$ phase was unlikely to have occurred due to experimental error, especially if we take 
into account the $\gamma^{\mathrm{s}}$ stabilization in the homogenized state. ${ }^{[24]}$ It is reasonable to assume that recrystallization created some preferential orientation, and this orientation favored the formation of $\gamma^{\mathrm{o}}$ instead $\gamma^{\mathrm{s}}$ in the quench process.

The $\gamma \rightarrow \gamma^{\mathrm{s}} \rightarrow \gamma^{\mathrm{o}} \rightarrow \alpha^{\prime \prime}$ transformations are produced only by shear. ${ }^{[9]}$ If one or two $\gamma$ orientations are preferred in the recrystallization, then the transformation $\gamma \rightarrow \gamma^{\circ}$ may be preferred. This effect was observed



Fig. 8-XRD patterns of the alloy U-7.5Nb-2.5Zr cold rolled (degree of deformation 20 and $80 \mathrm{pct}$ ) subjected to isothermal annealing at $973 \mathrm{~K}\left(700^{\circ} \mathrm{C}\right)$ for 1 and $4 \mathrm{~h}$ compared to the homogenized (1273 K/5 h Ref. [24]) and deformed states (20 and 80 pct). experimentally by Yakel $^{[35]}$ and Hatt and Stewart ${ }^{[36]}$ for the $\gamma^{\circ} \rightarrow \alpha^{\prime \prime}$ transformation. This could be the reason for the formation of $\gamma^{\circ}$ observed in the results reported herein.

Based on these results, it can be concluded that the retention of the preferred orientation through metastable phase transition could play a major role during the treatment of some $\gamma$ quenched uranium alloys. This effect can be used to optimize the retention of $\gamma^{\mathrm{s}}$ though a texture that offers a maximum opposition to the transformation $\gamma^{\mathrm{s}} \rightarrow \gamma^{\mathrm{o}}$.

The effect of annealing for 4 hours on microstructure produced the beginning of exaggerated grain growth in both degrees of deformation (Figure 9). As the abnormal growth is associated only with prolonged annealing time, it has reinforced the idea of the occurrence of secondary recrystallization. Secondary recrystallization occurs more frequently in materials with dispersion of precipitates, strong crystallographic texture, or limitations imposed by the sample thickness. In the present case, the growth is due to the inhibition of normal grain growth, i.e., an inhibitory mobility effect acts on most of the grain boundaries leaving only a few grain boundaries with mobility to grow in the matrix.

Representative optical metallography for the deformed 50 pct alloy, and annealed at $973 \mathrm{~K}\left(700{ }^{\circ} \mathrm{C}\right)$ for 1 hour is provided in Figure 10. This structure possesses a Vickers hardness of $157.7 \mathrm{HV}$, close to the initial value (173.93 HV, see Reference 24), in opposition to that observed in a previous work ${ }^{[22]}(421.86 \mathrm{HV})$. The behavior observed in the previous work in Reference 22, which also differs from that reported in the literature, ${ }^{[21]}$ may be a result of heterogeneities influence, caused by the different melting processes.

Figures 11 and 12 provide the response surface and contour plot, respectively, generated through the data obtained.

Table III shows Standard deviation, R-squared, Adjusted R-Squared, and Predicted R-Squared for the quadratic model assumed in temperature variable. These values confirm a good fit of the model with the data.


Fig. 9-Micrographs of cold-rolled U-7.5Nb-2.5Zr alloy with degree of reduction of 20 pct $(a)$ and 80 pct $(b)$, annealed at $973 \mathrm{~K}\left(700{ }^{\circ} \mathrm{C}\right)$ for $4 \mathrm{~h}$. Observed evidence of the beginning of exaggerated grain growth (arrows). 




Fig. 10-Sample optical metallograph taken parallel to the rolling direction for U-7.5 Nb-2.5Zr alloy deformed 50 pet and annealed at $973 \mathrm{~K}\left(700^{\circ} \mathrm{C}\right)$ for $1 \mathrm{~h}$.

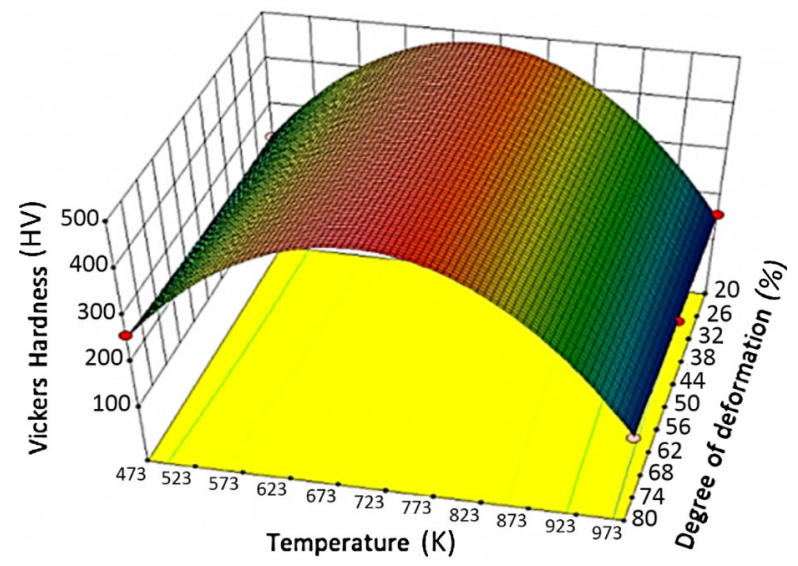

Fig. 11-Response surface generated from a quadratic model in the optimization of two variables (Annealing temperature and Degree of deformation). Variable time sets in $1 \mathrm{~h}$.
The normal probability plot of residuals is provided in Figure 13. Residual plotted points are very close to the linear trend which helps to validate the model for response surface. ${ }^{[23]}$

The response surface obtained shows a similar profile to that observed in previous work ${ }^{[22]}$ and by Peterson and Vandevoort, ${ }^{[21-24]}$ i.e., an increase in the hardness from $473\left(200{ }^{\circ} \mathrm{C}\right)$ up to $773 \mathrm{~K}\left(500{ }^{\circ} \mathrm{C}\right)$, followed by a decrease after $873 \mathrm{~K}\left(600{ }^{\circ} \mathrm{C}\right)$. It is thus possible to say that, in general terms, the behavior of the U-7.5Nb-2.5Zr alloy with respect to recovery, recrystallization, and precipitation phenomena will follow the response surface in which the most significant parameter is the temperature (first and second order). The first-order interaction between the parameters degree of deformation and time was not significant for the model. The reduced equation provided by the model is presented below:

$$
\begin{aligned}
\text { Hardness }(\mathrm{HV})= & -452.6-5.54(\mathrm{Def})+5.27(\mathrm{~T}) \\
& -82.96(\mathrm{t})-2.05 \times 10^{-3}(\mathrm{Def}) .(\mathrm{T}) \\
& -7.49 \times 10^{-3}(\mathrm{~T}) .(\mathrm{t})+0.069(\mathrm{Def})^{2} \\
& -5.8 \times 10^{-3}(\mathrm{~T})^{2}+18.68(\mathrm{t})^{2}
\end{aligned}
$$

With Def $=$ Degree of deformation (in pct). $T=$ Temperature (in ${ }^{\circ} \mathrm{C}$ ), $t=$ time (in hours).

The equation in terms of actual factors can be used to make predictions about the response for given levels of each factor.

Table III. Parameters for Analyzing the Response Surface Models

\begin{tabular}{lc}
\hline Parameters & Quadratic Model \\
\hline Std. Dev. & 13.60 \\
R-squared & 0.9926 \\
Adj R-squared & 0.9877 \\
Pred R-squared & 0.9713 \\
\hline
\end{tabular}
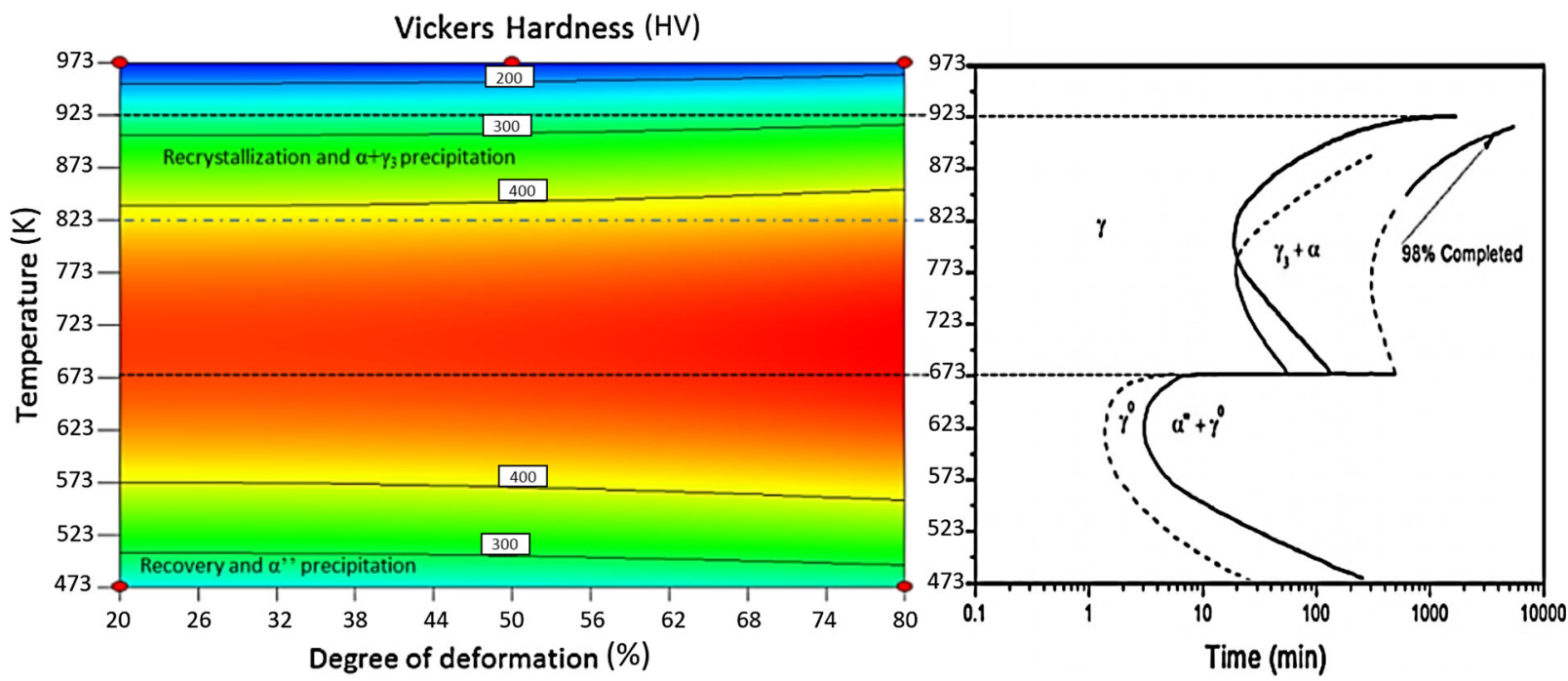

Fig. 12 - Contour plot generated from a quadratic model in the optimization of two variables (Temperature and Degree of deformation) and TTT diagram from Ref. [20] for U-7.5Nb-2.5Zr alloy. 1-h setting time. 


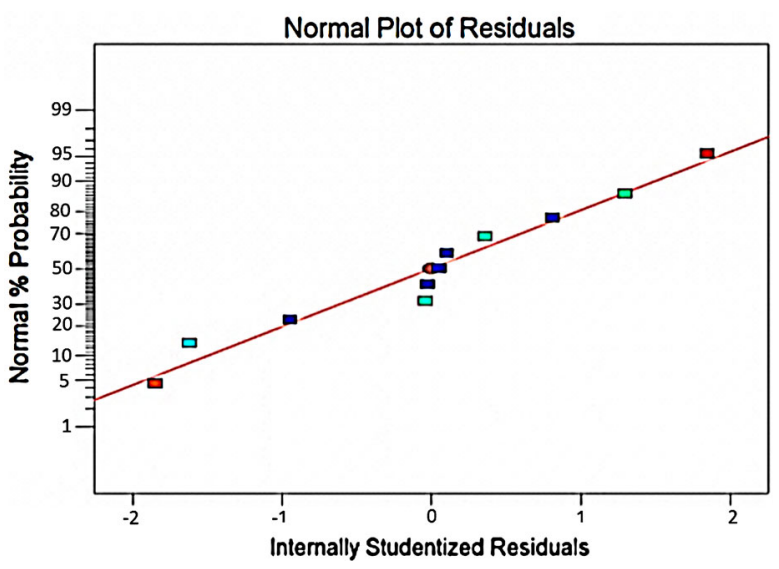

Fig. 13-Normal plot of residuals for the quadratic model.

The following points are emphasized regarding the response surface: precipitation hardening prevails for temperatures ranging from $673 \mathrm{~K}\left(400{ }^{\circ} \mathrm{C}\right)$ to about $823 \mathrm{~K}\left(550^{\circ} \mathrm{C}\right)$, regardless of the degree of reduction and annealing time. Phase precipitation $\alpha+\gamma_{3}$ and recrystallization interaction can occur only within a narrow temperature range between $848 \mathrm{~K}$ and $923 \mathrm{~K}\left(575^{\circ} \mathrm{C}\right.$ and $650{ }^{\circ} \mathrm{C}$ ). Annealing in this temperature range provides enough energy for migration of high-angle boundaries in the $\alpha+\gamma_{3}$ phases stability field, which tend to precipitation, since represents a considerable energy reduction to the system. Above $923 \mathrm{~K}\left(650{ }^{\circ} \mathrm{C}\right)$, recrystallization starts in the $\gamma$-phase field and is almost complete in 1 hour for all the degrees of deformation evaluated.

In the temperature range $473 \mathrm{~K}$ to $673 \mathrm{~K}\left(200{ }^{\circ} \mathrm{C}\right.$ to $400{ }^{\circ} \mathrm{C}$ ), an interaction occurs between the formation of metastable phases $\gamma^{\mathrm{o}} / \alpha^{\prime \prime}$, from the shear decomposition of $\gamma^{\mathrm{s}}$, and the phenomenon of recovery. Recovery will predominate for medium/high degrees of deformation.

\section{CONCLUSIONS}

The experimental data gathered in the present study represent the first generation of phase precipitation and recovery/recrystallization interaction for $\mathrm{U}-7.5 \mathrm{Nb}-2.5 \mathrm{Zr}$ alloy. The observations of the study may be summarized as follows:

- In the temperature range $473 \mathrm{~K}$ to $673 \mathrm{~K}\left(200{ }^{\circ} \mathrm{C}\right.$ to $400{ }^{\circ} \mathrm{C}$ ), interactions occur between the isothermal martensitic shear transformation $\gamma^{\mathrm{o}} \rightarrow \alpha^{\prime \prime}$ and the phenomenon of recovery. Recovery will prevail for medium and high degrees of deformation.

- The process parameter which most influences the interaction between phase precipitation and recrystallization is temperature. Interaction between equilibrium phases $\alpha+\gamma_{3}$ and recrystallization is plausible only in a narrow temperature range, between $848 \mathrm{~K}$ and $923 \mathrm{~K}\left(575^{\circ} \mathrm{C}\right.$ and $\left.650{ }^{\circ} \mathrm{C}\right)$. We expected this behavior to be repeated for alloys with close composition, such as $\mathrm{U}-9 \mathrm{Nb}-3 \mathrm{Zr}$, highly considered for monolithic fuel, with a further reduction in the temperature range.
- It was also possible to observe that low degrees of deformation generate heterogeneous recrystallization, producing regions with very small grain size.

- Annealing at $973 \mathrm{~K}\left(700{ }^{\circ} \mathrm{C}\right)$ for times up to 4 hours causes exaggerated grain growth.

- From the results, it was possible to observe that homogenization followed by quenching was efficient to retain $\gamma^{\mathrm{s}}$. However, recrystallization followed by quenching produces $\gamma^{\circ}$. These results suggest that the phase transformations of $\gamma \rightarrow \gamma^{\mathrm{s}} \rightarrow \gamma^{\mathrm{o}} \rightarrow \alpha^{\prime \prime}$, produced by shear, are strongly dependent on crystallographic orientations. This fact can be used to enhance the retention of the metastable $\gamma^{\mathrm{s}}$ phase.

This fundamental physical metallurgy study aims to be useful as a baseline for fabrication and aid to understanding fuel performance behavior analysis regarding monolithic fuels. This information might also be of interest to other researchers investigating the use of U$\mathrm{Nb}-\mathrm{Zr}$ alloys.

\section{REFERENCES}

1. Research Reactor Core Conversion from the Use of Highly Enriched Uranium to the Use of Low Enriched Uranium Fuels, Guidebook Addendum, Heavy Water Moderator Reactors, IAEA-TECDOC-233, Vienna, August 1980.

2. S.J. Zinkle and G.S. Was: Acta Mater., 2013, vol. 61, pp. 735-58.

3. D.R. Olander: Fundamental Aspects of Nuclear Reactor Fuel Elements, Technical Information Center, Springfield, 1976.

4. K.H. Eckelmeyer: ASM Handbook. Properties and Selection: Nonferrous Alloys and Special Purpose Materials, American Society of Metals, Materials Park, 1990, vol. 2.

5. B.R.T. Frost: Nuclear Fuel Elements-Design, Fabrication and Performance, 1st ed., Pergamon Press Inc, Oxford, 1982.

6. Y. Arai, et al: Report IAEA-TECDOC-1374, International Atomic Energy Agency, Vienna, September 2003.

7. W.D. Wilkinson: Uranium Metallurgy, Interscience Publishers, New York, 1962, vol. II.

8. D. Blake and F. Hehemann: in Physical Metallurgy of Uranium Alloys, J.J. Burke, et al. eds. Brook Hill Publishing Company, Chestnut Hill, 1976, pp. 189-218.

9. H.L. Yakel: in Physical Metallurgy of Uranium Alloys, J.J. Burke, et al., eds., Brook Hill Publishing Company, Chestnut Hill, 1976, pp. 259-310.

10. G.L. Hofman and L.C. Walters: in Materials Science and Technology: Comprehensive Treatment, B.R.T. Frost, ed., Wiley VCH, Weinheim, 1994, vol. 10A.

11. H. Kreye and E. Horbogen: J. Mater. Sci., 1970, vol. 5, pp. 89-95.

12. H. Kreye, E. Horbogen, and F. Haessner: Phys. Status Solid, 1970, vol. 97 , pp. $97-108$.

13. K. Hornbogen and U. Köster: Recrystallization of Metallic Materials, Riederer Verlag GmbH, Stuttgart, 1978, p. 159.

14. O. Engler and P. Yang: Proc. 16th Riso International Symposium on Materials Science, N. Hansen et al. eds., Ros- kilde, Denmark, pp. 335-342, 1995.

15. F.J. Humphreys and M. Somerday: Proc. Int. Conf. Thermo-mechanical Processing: Mechanics, Microstructure and Control, E.J. Palmiere et al., eds., Sheffield, p. 46, 2003.

16. J.M. Fackelmann, A.A. Bauer and D.P. Moak: Report BMI-X10264, Battelle Memorial Institute, Columbus, July 1969. DOI: $10.2172 / 4077271$.

17. C.W. Dean: Report Y-1694, Oak Ridge Y-12 Plant, Tennessee, October 1969.

18. F. Giraud-Heraud and J. Guillaumi: Acta Met., 1973, vol. 21, pp. $1243-52$.

19. M.M. Karnowsky and R.W. Rohde: J. Nucl. Mat., 1973, vol. 49, pp. 81-90. 
20. R.A. Vandermeer: Proc. Conference on the Physical Metallurgy of Uranium Alloys, Vail, Colorado, Feb. 11-14, 1974.

21. C.A.W. Peterson and R.R. Vandervoot: Report UCRL-7869, Lawrence Radiation Laboratory, California, 1964.

22. D.A. Lopes, T.A.G. Restivo, and A.F. Padilha: J. Nucl. Mater., 2013, vol. 440, pp. 304-09.

23. M.A. Bezerra, R.E. Santelli, E.P. Oliveira, L.S. Villar, and L.A. Escaleira: Tantala, 2008, vol. 76, pp. 965-77.

24. D.A. Lopes, T.A.G. Restivo, and A.F. Padilha: J. Nucl. Mater., 2014, vol. 449, pp. 23-30.

25. LECO IR-412 Carbon Determinator Instruction Manual.

26. LECO TC-436 Nitrogen/Oxygen Analyzer Instruction Manual.

27. A.M. Kelly, R.D. Field, and D.J. Thomas: J. Nucl. Mater., 2012, vol. 429 , pp. $118-27$.

28. ASTM E112-96: Standard Test Methods for Determining Average Grain Size, ASM International, West Conshohocken, 2004.
29. A.C. Larson and R.B. Von Dreele: General Structure Analysis System (GSAS), Los Alamos National Laboratory Report LAUR 86-748, Los Alamos, USA, 2004.

30. D.E. Burkes, R. Prabhakaran, T. Hartmann, J.F. Jue, and F.J. Rice: Nucl. Eng. Des., 2010, vol. 240, pp. 1332-39.

31. K.H. Eckelmeyer: ASM Handbook. Metallography and Microstructure, American Society for Metals, Ohio, 1985, vol. 9, pp. 476-87.

32. F.J. Humphrey and M. Hatherly: Recrystallization and Related Annealing Phenomena, 2nd ed., Pergamon, Oxford, 1996.

33. C.W. Jacob and B.E. Warren: J. Am. Chem. Soc., 1937, vol. 59, pp. 2588-91.

34. U. Koster: Met. Sci. J., 1974, vol. 8, pp. 151-60.

35. H.L. Yakel: J. Nucl. Mater., 1969, vol. 33, pp. 286-95.

36. B.A. Hatt and D. Stewart: Report No. R 189/10, Fulmer Research Institute Ltd. for the Atomic Energy Research Establishment, Harwell, England, August 1967. 